\title{
Optogenetic Stimulation of MCH Neurons Increases Sleep
}

\author{
Roda Rani Konadhode, ${ }^{2 *}$ Dheeraj Pelluru, ${ }^{2 *}$ Carlos Blanco-Centurion, ${ }^{2}$ Andrew Zayachkivsky, ${ }^{4}$ Meng Liu, ${ }^{2}$ \\ Thomas Uhde, ${ }^{2}$ W. Bailey Glen Jr, ${ }^{3}$ Anthony N. van den Pol, ${ }^{4}$ Patrick J. Mulholland, ${ }^{2,3}$ and Priyattam J. Shiromani ${ }^{1,2}$ \\ ${ }^{1}$ Ralph H. Johnson VA Medical Center, ${ }^{2}$ Departments of Psychiatry and Behavioral Sciences, and ${ }^{3}$ Neurosciences, Medical University of South Carolina, \\ Charleston, South Carolina 29425, and ${ }^{4}$ Department of Neurosurgery, Yale University School of Medicine, New Haven, Connecticut 06520
}

Melanin concentrating hormone $(\mathrm{MCH})$ is a cyclic neuropeptide present in the hypothalamus of all vertebrates. MCH is implicated in a number of behaviors but direct evidence is lacking. To selectively stimulate the MCH neurons the gene for the light-sensitive cation channel, channelrhodopsin-2, was inserted into the MCH neurons of wild-type mice. Three weeks later MCH neurons were stimulated for $1 \mathrm{~min}$ every $5 \mathrm{~min}$ for $24 \mathrm{~h}$. A $10 \mathrm{~Hz}$ stimulation at the start of the night hastened sleep onset, reduced length of wake bouts by $50 \%$, increased total time in non-REM and REM sleep at night, and increased sleep intensity during the day cycle. Sleep induction at a circadian time when all of the arousal neurons are active indicates that $\mathrm{MCH}$ stimulation can powerfully counteract the combined wake-promoting signal of the arousal neurons. This could be potentially useful in treatment of insomnia.

\section{Introduction}

Wake, non-REM sleep, and REM sleep are regulated by a coordinated interaction between specific neurons in the hypothalamus and brainstem (Jones, 2011). The arousal groups are collectively represented by neurons that contain acetylcholine, histamine, norepinephrine, and serotonin, or specific peptides such as orexin (also known as hypocretin) (Jones, 2011). The sleep-active neurons are present in the medial and ventral lateral preoptic area, the basal forebrain, and the posterior hypothalamus (Jones, 2011). Optogenetic stimulation of the arousal neurons awakens the animal (Adamantidis et al., 2007; Carter et al., 2010), which strengthens their position in network models of sleep-wake regulation. However, it is not known whether such selective stimulation of sleep-active neurons also produces sleep.

One sleep-active neuronal group contains melanin concentrating hormone (MCH) (Hassani et al., 2009). MCH neurons are located in the hypothalamus and project widely throughout the brain, including to the arousal neurons (Bittencourt et al., 1992). In the present study, the gene for channelrhodopsin-2 (ChR2) was inserted using an $\mathrm{MCH}$ promoter whose specificity has been established (van den Pol et al., 2004). We demonstrate that optogenetic stimulation of $\mathrm{MCH}$ neurons increases sleep against a strong waking drive. Thus, $\mathrm{MCH}$ neurons are candidate sleep neurons in network models of sleep-wake regulation.

Received March 21, 2013; revised April 16, 2013; accepted May 14, 2013.

Author contributions: A.N.v.d.P., P.J.M., and P.J.S. designed research; R.R.K., D.P., C.B.-C., A.Z., M.L., W.B.G., and P.J.M. performed research; T.U. and A.N.v.d.P. contributed unpublished reagents/analytic tools; R.R.K., D.P., C.B.-C., M.L., W.B.G., A.N.v.d.P., P.J.M., and P.J.S. analyzed data; A.N.v.d.P. and P.J.S. wrote the paper.

This work was supported by NIH grants AA017922, MH055772, NS052287, NS079940, and NS48476 and the Medical Research Service of the Department of Veterans Affairs. We thank Dr. Mahesh Thakkar for helpful comments during the writing of this manuscript, and Sundaravadivel Balasubramanian for assistance with the confocal microscope.

${ }^{*}$ R.R.K. and D.P. contributed equally to this work.

Correspondence should be addressed to Dr. Priyattam J. Shiromani, Ralph H. Johnson VA Medical Center, Medical University of South Carolina, Department of Psychiatry, 114 Doughty Street, MSC 404/STB 404, Charleston, SC 29425. E-mail:shiroman@musc.edu.

DOI:10.1523/JNEUROSCI.1225-13.2013

Copyright $\odot 2013$ the authors $\quad 0270-6474 / 13 / 3310257-07 \$ 15.00 / 0$

\section{Materials and Methods}

pAAV-MCH-ChR2(H134R)-EYFP plasmid construction. The genes for ChR2 (H134R) and the reporter, EYFP, were fused through NotI enzyme site to express both genes as fusion proteins (from Karl Diesseroth) and expressed only in MCH neurons by excising the human synapsin promoter between MluI and SalI sites and replacing it with $\mathrm{MCH}$ promoter (462 bp). The plasmid was packaged in AAV stereotype 5 virus with titer of $5 \times 10^{12}$ (University of North Carolina, Chapel Hill, NC). rAAVMCH-GFP, was used as described previously (Liu et al., 2011) and represented control without $\mathrm{ChR} 2$.

Delivery of virus and implant of sleep electrodes. rAAV-MCHChR2(H134R)-EYFP or rAAV-MCH-GFP were stereotaxically injected (2\% isoflurane; Institutional Animal Care and Use Committee guidelines) into the hypothalamus of 5-month-old C57BL/6J mice (The Jackson Laboratory; either sex). Four injections in each mouse (two each hemisphere; $750 \mathrm{nl}$ each site) targeted the medial and lateral MCH neurons. At this time, the sleep electrodes were also implanted (Liu et al., 2011).

In vitro slice electrophysiology. The 30-40 d after viral injection, brains were removed (decapitation; $2 \%$ isoflurane) and slices $(220 \mu \mathrm{m})$ were incubated in artificial CSF (ACSF) at $34^{\circ} \mathrm{C}$ for $1 \mathrm{~h}$. Slices were transferred to a submerged recording chamber, held at $34^{\circ} \mathrm{C}$, and bathed in recording ACSF. Incubation and recording buffers were continuously aerated with 5\% carbon dioxide/95\% oxygen. Voltage-clamp and cell-attached recordings were obtained from $\mathrm{MCH}$ neurons identified visually with Dodt contrast optics using an Axio Examiner D1 microscope fitted with fluorescence; for current-clamp recordings cells were detected with Olympus BX51WI DIC/Fluorescence microscope. EYFP-positive MCH neurons were stimulated with $10 \mathrm{~ms}$ blue light pulse trains (473 nm DPSS Laser; OEM Laser Systems) at 5, 10, 20, and $30 \mathrm{~Hz}$ for $1 \mathrm{~s}$ with intertrain intervals of $5 \mathrm{~s}$. In current-clamp, cells were stimulated with a Bridgelux BXRAC2002 LED array driven by a Luxdrive BuckBlock A009 constant current driver; timing (10 ms) and frequency $(1,10,20$, and $30 \mathrm{~Hz})$ of stimulation were set with a Grass S44 stimulator. To mimic in vivo stimulation conditions, EYFP-positive MCH neurons were stimulated with light pulse trains at $10 \mathrm{~Hz}$ for $1 \mathrm{~min}$ with an intertrain interval of $1 \mathrm{~min}$, and recordings were performed over a $10 \mathrm{~min}$ period. An input-output relationship was obtained by varying the intensity of a $1 \mathrm{~s}$ blue light pulse, and steady-state amplitude was determined at 900-950 ms for each pulse. 
Sleep recording. Ten days after surgery the mice were tethered to lightweight recording cables mounted to swivels and adapted for $10 \mathrm{~d}$. The swivels passed through electrical and fiber optic signals allowing the mice unimpeded freedom of movement. On day 21, a 48 h electroencephalogram (EEG) and video recording was made (represents $0 \mathrm{~Hz}$ ). The EEG was recorded from two contralateral screws (frontaloccipital). The electromyography (EMG) signal was recorded from nuchal muscles. The EEG and EMG signals were amplified via a Grass polygraph and recorded onto the hard disk using an analog-digital board (Kissei Comtec). The animals were housed singly in Plexiglas cages with bedding; food and water were available ad libitum. The temperature in the sleep recording room was $25^{\circ} \mathrm{C}$ and a $12 \mathrm{~h}$ light/dark cycle (6:00 A.M.-6:00 P.M. lights on; 100 lux) was maintained.

Immunohistochemistry. Perfused brains were cut ( $40 \mu \mathrm{m}$ coronal sections; 1 in 4 series) and the free-floating sections were incubated overnight in a primary antibody (rabbit anti-MCH, 1:1000 dilution;Phoenix Pharmaceutical); goat antiorexin (1:500; Santa Cruz Biotechnology); rabbit anti-histidine decarboxylase (1:200; American Research Products); or rabbit anti-tyrosine hydroxylase (1:200; Millipore) followed by $2 \mathrm{~h}$ incubation in the secondary antibody (anti-rabbit or anti goat-Alexa Fluor 568; 1:500; Invitrogen). The sections were washed, mounted onto gelatin-coated slides, and coverslipped. The fluorescent images were visualized with a Leica confocal microscope and colocalization with EYFP was done by $3 \mathrm{D}$ view software on $Z$-stack scan of $2-\mu \mathrm{m}$-thick slices. Tally of EYFP and $\mathrm{MCH}-$ positive neurons were made from on average 7.8 $( \pm 0.6)$ sections (wells 1 and 3$)$ in the 14 mice whose sleep was recorded.

Identification of sleep-wake states. The $48 \mathrm{~h}$ EEG, EMG, and video recordings were scored manually on a computer (SleepSign Software) in $12 \mathrm{~s}$ epochs for wake, non-REM sleep, and REM sleep (Liu et al., 2011). Wakefulness was identified by the presence of desynchronized EEG, and high EMG activity. Non-REM sleep consisted of high amplitude slow waves together with a low EMG tone relative to waking. REM sleep was identified by the presence of regular EEG theta activity coupled with low EMG relative to slow-wave sleep. After the EEG data were scored, the code was broken to reveal the identity of each mouse.

Analysis of the EEG frequency (fast Fourier transform). Fast Fourier transform (FFT) raw values during wake, non-REM, and REM sleep were automatically calculated by the software (SleepSign) in $0.5 \mathrm{~Hz}$ bins. Because of variability FFT values were normalized by dividing the raw value of EEG power during non-REM sleep by the average of total EEG power for the spectrum $(0.5-32 \mathrm{~Hz})$ across $24 \mathrm{~h}$.

Statistical analysis. One-way repeated-measures ANOVA with post $h o c$, or a priori paired $t$ test $(p<0.05)$.

\section{Results}

\section{ChR2-EYFP is expressed only in MCH neurons}

rAAV-MCH-ChR2(H134R)-EYFP was injected into two sites in each hemisphere since the MCH neurons are distributed over a much wider area of the posterior hypothalamus compared with
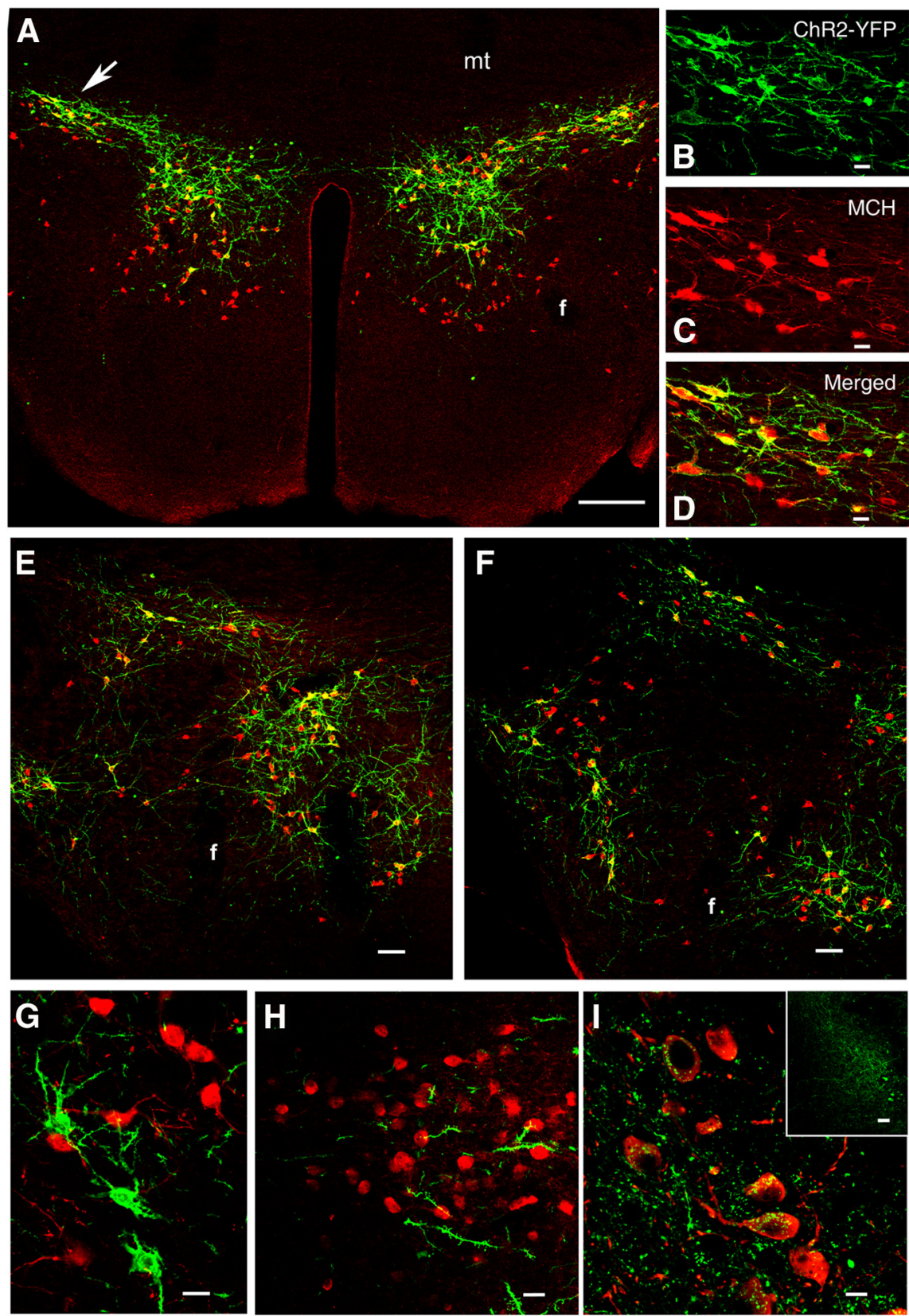

Figure 1. Distribution of MCH-ChR2(H134R)-EYFP-positive neurons in the posterior hypothalamus. $\boldsymbol{A}-\boldsymbol{F}$, Photomicrograph depicts the distribution of neurons containing MCH (red) and EYFP (green) in two representative WT mice given rAAV-MCHChR2(H134R)-EYFP in the hypothalamus. $\boldsymbol{B}-\boldsymbol{D}$, Higher magnification of the area denoted by the arrow in $\boldsymbol{A}$ and shows that all ChR2-EYFP neurons are also MCH positive. $G$, The arousal orexin-immunoreactive neurons (red) are intermingled with the MCH-ChR2-EYFP neurons (green). $\boldsymbol{H}$, MCH-ChR2-EYFP neurons (green) innervate the arousal histidine decarboxylase neurons in the tuberomammillary nucleus (red). I, MCH-ChR2-EYFP terminals surround the tyrosine hydroxylase-immunoreactive neurons of the locus ceruleus (red). II Inset depicts dense MCH projections (green) into the locus ceruleus. Scale bars: (in $\boldsymbol{A}$ ) $220 \mu \mathrm{m}$; (in $\boldsymbol{E}, \boldsymbol{F}$ ) $100 \mu \mathrm{m}$; (in $\boldsymbol{B}-\boldsymbol{D}, \boldsymbol{G}, \boldsymbol{H}$ ) $20 \mu \mathrm{m}$; (in $\boldsymbol{I}$ ) $15 \mu \mathrm{m}$. f, fornix; mt, mammillothalamic tract.

the orexin neurons (Elias et al., 2001). The MCH neurons dorsal to the fornix $(53.4 \pm 6.4 \%)$, especially in the zona incerta, were also EYFP positive (Fig. $1 A-F$ ). However, in the ventral and lateral hypothalamus only $19.6 \%( \pm 1.8)$ of $\mathrm{MCH}$ neurons contained EYFP. All EYFP-positive neurons were $\mathrm{MCH}$ positive. EYFP-positive but MCH-negative neurons were not evident. $\mathrm{MCH}-\mathrm{ChR} 2-\mathrm{EYFP}$-positive neurons were intermingled with the arousal orexin neurons (1G) and EYFP-positive axons innervated downstream arousal neurons in the tuberomammillary nucleus $(1 \mathrm{H})$ and the locus ceruleus (1I). 


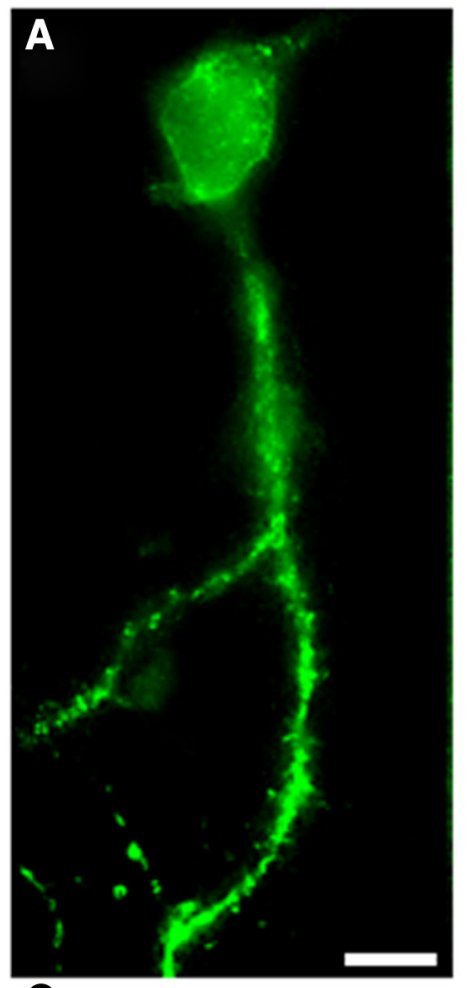

\section{C}

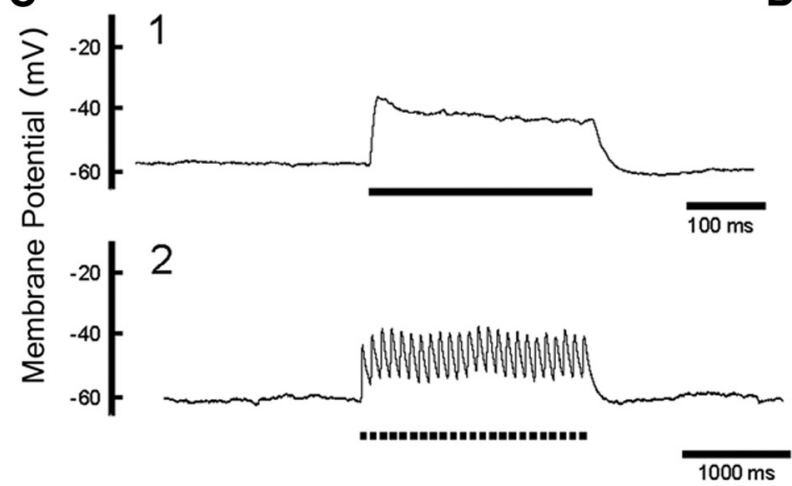

E

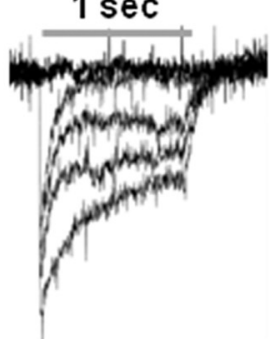

G

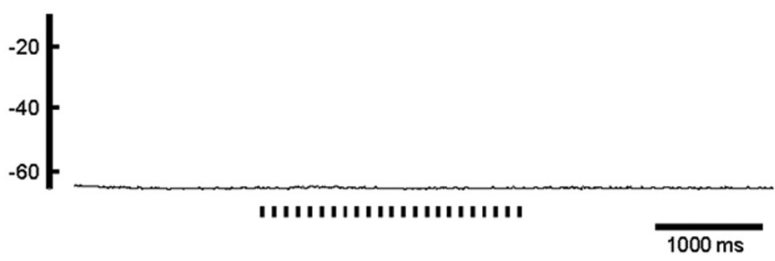

B

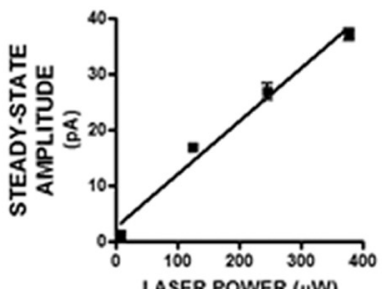

1

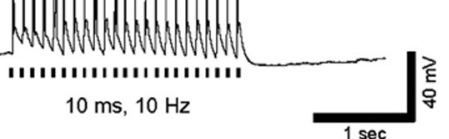

2

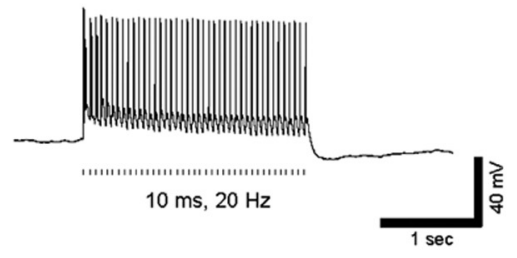

3

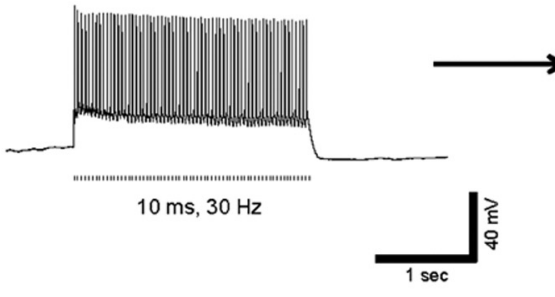

D

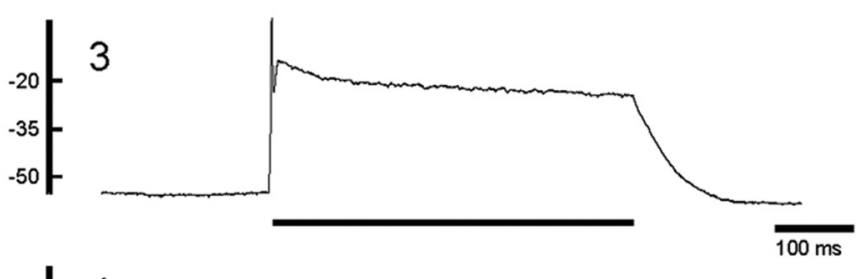

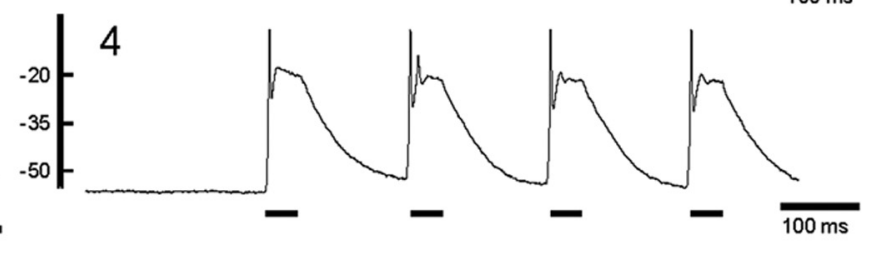

$\mathbf{F}$

F

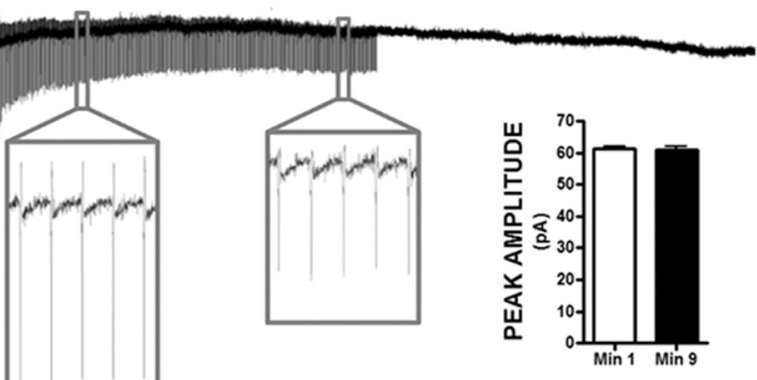

Figure 2. MCH-ChR2(H134R)-EYFP containing neurons respond to $473 \mathrm{~nm}$ light. $\boldsymbol{A}$, Representative image of an EYFP-positive neuron in an acute brain slice sensitive to blue laser stimulation. Scale bar, $20 \mu \mathrm{m}$. $\boldsymbol{B}$, Whole-cell current-clamp recordings demonstrate action potentials at each suprathreshold light stimulus with $10 \mathrm{~ms}$ pulses of light ( $\boldsymbol{B}$, see temporal expansion; $5 \mathrm{~Hz}$ not shown). $\boldsymbol{C}$, Subthreshold stimulation induced depolarization with no action potentials. $\boldsymbol{D}$, Sustained light stimulation ( $500 \mathrm{~ms}, 50 \mathrm{~ms})$ induced an action potential followed by a prolonged depolarization. $\boldsymbol{E}$, Peak and steady state current increased as a function of light intensity. $\boldsymbol{F}$, Representative trace of 1 min stimulation at $10 \mathrm{~Hz}$ followed by a 1 min period without stimulation. This stimulation protocol was repeated for $10 \mathrm{~min}$. Although amplitude was reduced, spikes were generated during the entire 1 min period of stimulation. Bar graph shows that peak amplitude of responses during the last $10 \mathrm{~s}$ of the first and ninth minute of the $10 \mathrm{~min}$ epoch was similar. $\mathbf{G}$, Control cell lacking ChR2 showed no response to light stimulation at $10 \mathrm{~ms} 10 \mathrm{~Hz}$. 

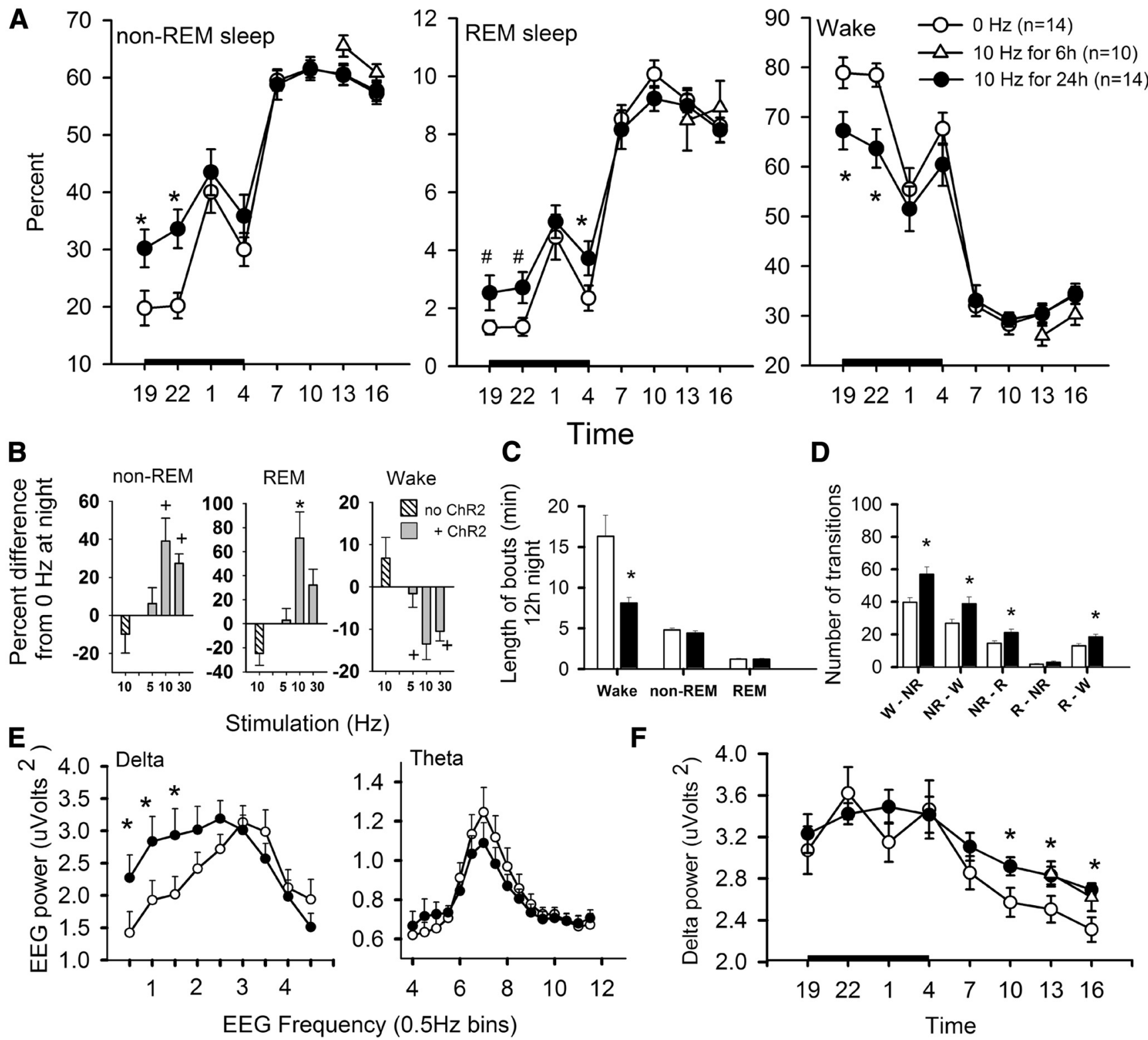

Figure 3. Sleep is increased in response to optogenetic stimulation of rAAV-MCH-ChR2-EYFP neurons. $\boldsymbol{A}$, Effect of optogenetic stimulation on non-REM, REM sleep, and wake across the $24 \mathrm{~h}$. Closed circles represent mice that were stimulated for $24 \mathrm{~h}$ starting at night, while the open triangles represent the same animals stimulated for $6 \mathrm{~h}$ in the second half of the day cycle. $\boldsymbol{B}$, The average percentage difference from $0 \mathrm{~Hz}$ during the $12 \mathrm{~h}$ night period. Hatched bar represents mice $(n=7)$ without $\mathrm{ChR2}$ but stimulated at $10 \mathrm{~Hz}$. $\boldsymbol{C}$, Average length (minutes) of episodes at night in mice with ChR2 stimulated at $0 \mathrm{~Hz}$ (open bar) or $10 \mathrm{~Hz}$ (black bar). $\boldsymbol{D}$, Average number of transitions between the three sleep-wake states at night in mice with ChR2 stimulated at $0 \mathrm{~Hz}$ (open bar) or 10 $\mathrm{Hz}$ (black bar). Daytime data for length and transitions is provided in Figure 4. $\boldsymbol{E}$, EEG power in the delta and theta frequencies in mice with ChR2 stimulated at $0 \mathrm{~Hz}$ (open circle) or $10 \mathrm{~Hz}$ (closed circle). $\boldsymbol{F}$, Waxing and waning of delta power $\left(0.5-4 \mathrm{~Hz}\right.$ ) across the night and day in mice with ChR2 stimulated at $0 \mathrm{~Hz}$ (open circle) or $10 \mathrm{~Hz}$ (closed circle). ${ }^{*} p<0.05 \mathrm{versus} 0 \mathrm{~Hz}$. ${ }^{\#} p<0.05 \mathrm{versus} 0 \mathrm{~Hz}$ for the two time periods. ${ }^{+} p<0.05$ versus 0 or $5 \mathrm{~Hz}$. Black bar on the abscissa in $\boldsymbol{A}$ and $\boldsymbol{F}$ denotes the $12 \mathrm{~h}$ night period.

\section{MCH-ChR2-EYFP neurons are stimulated by blue}

\section{$(473 \mathrm{~nm})$ light}

In vitro experiments confirmed that EYFP labeled neurons were sensitive to $473 \mathrm{~nm}$ blue light and readily followed light-pulse stimulation (Fig. 2B). EYFP-positive neurons faithfully followed photostimulation at all frequencies tested (Fig. $2 B-D ; 5 \mathrm{~Hz}$ not shown). In addition, ChR2-EYFP-positive neurons demonstrated a near-linear increase in the steady-state amplitude as a function of an increase in the intensity of the laser power (Fig. $2 E)$. In one protocol relevant to the paradigm used for the behavioral studies the neurons were stimulated for $1 \mathrm{~min}$ and then not stimulated for $1 \mathrm{~min}$. This cycle was repeated for $10 \mathrm{~min}$. Blue light pulses at $10 \mathrm{~Hz}$ for $1 \mathrm{~min}$ generated action potentials for the duration of the stimulation epoch (Fig. $2 F$ ). Importantly, the peak amplitude of the photo-stimulated responses during the last $10 \mathrm{~s}$ of the first minute did not differ from the peak amplitude of the responses measured during the last $10 \mathrm{~s}$ of the ninth minute of stimulation (Fig. 2F, bar graph). Cells with no ChR2 expression were not responsive to light stimulation (Fig. $2 G$ ). These data confirm that EYFP-positive neurons express functional ChR2 channels that reliably and precisely respond to stimulation across a range of frequencies without diminishing over time.

Sleep is increased with MCH-ChR2-EYFP neuron stimulation The effect of optogenetic stimulation of the $\mathrm{MCH}$ neurons on sleep-wake behavior was next examined. Wild-type (WT) mice 
A
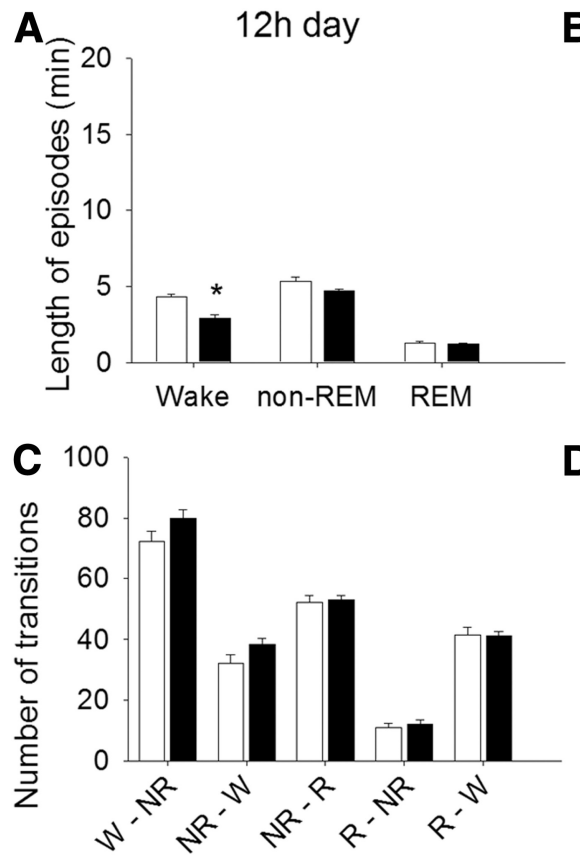

B

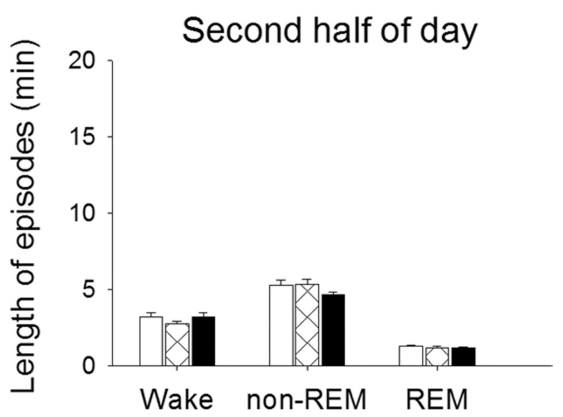

D

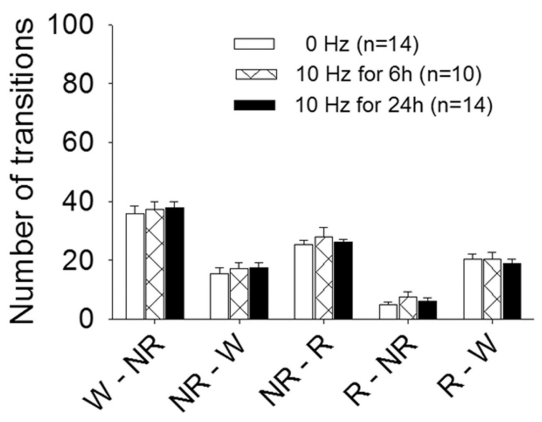

Figure 4. Average length of episodes (in minutes) and number of transitions during the $12 \mathrm{~h}$ day cycle $(\boldsymbol{A}, \boldsymbol{C})$ or during the second half of the day cycle $(\boldsymbol{B}, \boldsymbol{D})$ in ChR2-positive mice stimulated with 0 or $10 \mathrm{~Hz}$ stimulation. Length of waking bouts was significantly decreased during the day $\left({ }^{*} p<0.05\right)$.

(5-7 months old; $26 \mathrm{~g} \pm 0.7 ; 10$ males; $n=14$ ) were injected with the rAAV-MCH-ChR2(H134R)-EYFP into the posterior hypothalamus and sleep-wake behavior was recorded beginning 3 weeks after ChR2 gene delivery. A $48 \mathrm{~h}$ baseline recording $(0 \mathrm{~Hz})$ was obtained and then the fiber optic probes were inserted into the guide cannulas (mice were gently restrained). To discount the effect of cannula insertion on sleep we waited for $72 \mathrm{~h}$ after probe insertion to start optogenetic stimulation.

To better understand the effects of $\mathrm{MCH}$ stimulation in promoting sleep, light stimulation was applied at two phases in the circadian sleep cycle. In the first experiment, MCH stimulation began at the start of the animal's active period (lights-off cycle). We hypothesized that for $\mathrm{MCH}$ to be considered as part of the network promoting sleep $\mathrm{MCH}$ neuronal stimulation should induce sleep during the animal's wake-active cycle. In nocturnal rodents such as the WT mice used in this study the light-dark cycle strongly entrains the sleep-wake cycle and lights off is the signal to awaken, and to eat and drink. A clear day-night circadian rhythm in sleep-wake was evident in the mice (Fig. 3A). At the start of the lights-off (night) period the mice were stimulated with $5 \mathrm{~Hz}, 10 \mathrm{~Hz}$, or $30 \mathrm{~Hz}$ (random order) of $473 \mathrm{~nm}$ light pulses (10 ms duration; $1 \mathrm{~mW}$ at the tip). The light pulses were delivered for $1 \mathrm{~min}$ every $5 \mathrm{~min}$ for $24 \mathrm{~h}$, and $36 \mathrm{~h}$ elapsed between the three stimulation rates.

The $10 \mathrm{~Hz}$ light pulses were most effective in increasing sleep (Fig. 3B). The 10 and $30 \mathrm{~Hz}$ stimulation at the start of the night cycle significantly reduced by almost sixfold and threefold, respectively, the time to sleep onset compared with $0 \mathrm{~Hz}(0 \mathrm{~Hz}=$ $41.8 \mathrm{~min} \pm 14.24 ; 10 \mathrm{~Hz}=7.27 \mathrm{~min} \pm 3.16 ; 30 \mathrm{~Hz}=12.94 \pm$ $3.16 ; F=5.29 ; \mathrm{df}=2,41 ; p=0.012)$. Time to REM sleep onset was almost halved but it was not significant $(0 \mathrm{~Hz}=110.46$ $\min \pm 23.2 ; 10 \mathrm{~Hz}=59.37 \pm 29.59 ; 30 \mathrm{~Hz}=77.31 \pm 25.91)$. The $5 \mathrm{~Hz}$ stimulation did not decrease time to sleep $(66.03 \pm 34.82)$ or REM sleep $(90.17 \pm 40.3)$ onset. In the first hour of night stimulation, 10 and $30 \mathrm{~Hz} \mathrm{MCH}$ stimulation increased non-REM sleep time by $96.3 \%$ (19.82 $\min \pm 2.41$; $p=0.00015)$ and $68 \%$ (16.99 $\mathrm{min} \pm 2.13$; $p=0.005)$, respectively, compared with 0 $\mathrm{Hz}$ (10.09 $\mathrm{min} \pm 1.53)$. In the first hour, 5 $\mathrm{Hz}$ stimulation also increased non-REM sleep (14.56 min \pm 2.53 ) but it was not significant compared with $0 \mathrm{~Hz}$.

In the first $6 \mathrm{~h}$ of $10 \mathrm{~Hz} \mathrm{MCH}$ stimulation there was a $59.7 \%$ increase in non-REM sleep $(p=0.0004)$ and a 94.7\% $(p=0.002)$ increase in REM sleep (Fig. $3 A$, closed circles) compared with 0 $\mathrm{Hz}$. The $30 \mathrm{~Hz}$ stimulation produced a $44 \%$ increase in non-REM sleep ( $p=$ 0.007 ) and a $73.2 \%$ increase in REM sleep $(p=0.02)$. The $5 \mathrm{~Hz}$ stimulation was not effective. In the $12 \mathrm{~h}$ night period, 10 and $30 \mathrm{~Hz}$ light pulses significantly increased percentage non-REM $(F=7.7 ; \mathrm{df}=3,55$; $p=0.001)$ and REM sleep $(F=5.51 ; \mathrm{df}=$ $3,55 ; p=0.003)$ and decreased waking $(F=7.88 ; \mathrm{df}=3,55 ; p=0.001)$ compared with $0 \mathrm{~Hz}$ (Fig. $3 B$ ). $\mathrm{MCH}$ stimulation had no significant effect on non-REM, REM sleep, or wake during the day cycle, perhaps because of a ceiling effect. Over the course of $24 \mathrm{~h}, 10$ and $30 \mathrm{~Hz}$ light pulses produced a significant increase in total sleep $(F=6.17$; $\mathrm{df}=3,55 ; p=0.002)$ and in non-REM sleep $(F=6.26$; $\mathrm{df}=3,55$; $p=0.001)$ but not REM sleep. Light stimulation did not increase sleep in WT mice lacking ChR2 in MCH neurons $(n=7)$ (Fig. $3 B$, hatched bar).

\section{Length of wake bouts is decreased}

At night WT mice are awake for long periods. During this time 10 $\mathrm{Hz}$ stimulation decreased in half the average length of wake bouts (Fig. 3C), but there was no change in the length of non-REM or REM sleep bouts. Length of wake bouts was also significantly decreased during the day (Fig. $4 A$ ). At night, $10 \mathrm{~Hz}$ stimulation increased the transitions from wake to non-REM and non-REM to REM sleep bouts (Fig. 3D). Transitions from non-REM sleep to waking also increased at night but because the waking bouts were short the mice often re-entered into non-REM sleep increasing overall sleep times. Thus, with $10 \mathrm{~Hz}$ stimulation the increase in sleep at night was from shorter wake bouts and more sleep bouts.

Might MCH stimulation increase sleep if it was freshly applied during the animal's circadian sleep cycle? To answer this question, in the second experiment, $10 \mathrm{~Hz}$ stimulation was applied only during the second half of the lights-on period. In this experiment $(n=10) \mathrm{MCH}$ stimulation ( $1 \mathrm{~min}$ on $-4 \mathrm{~min}$ off) was started $6 \mathrm{~h}$ into the day cycle and continued for the remaining $6 \mathrm{~h}$ of the day cycle. Six of the 10 mice were exposed to the stimulation for the first time, while four mice were stimulated $36 \mathrm{~h}$ after completing the series of nighttime stimulations. The $10 \mathrm{~Hz}$ stimulation during the second half of the day cycle (Fig. $3 A$, open triangles) had no effect on non-REM sleep, REM sleep, or waking compared with $0 \mathrm{~Hz}$. The length or number of bouts of sleepwake did not increase either (Fig. 4).

\section{EEG delta power is increased}

An electrophysiological index of sleep intensity is represented by the slow oscillations in the delta frequency range $(0.5-4 \mathrm{~Hz})$ 
during sleep (Borbély, 1982). These slow oscillations correspond to the synchronized up-down states of hyperpolarized thalamocortical and corticothalamic neurons (Steriade et al., 1993), and increased power of the delta waveform would indicate that $\mathrm{MCH}$ stimulation was driving, either directly or indirectly, these neurons. Indeed, the EEG frequency in the delta band was significantly slowed (Fig. 3E, closed circles). Therefore, the delta band during non-REM sleep was more closely analyzed for changes in the waxing and waning of delta power across the $24 \mathrm{~h}$ night-day cycle (Borbély, 1982). The $10 \mathrm{~Hz}$ MCH stimulation significantly blunted the waning of delta power during the day cycle (Fig. 3F, closed circles) indicating persistent increase in sleep intensity (Fig. $3 F$ ). Theta activity during REM sleep was not affected (Fig. $3 E$ ). There was no stimulus artifact in the EEG at the $10 \mathrm{~Hz}$ stimulation frequency (Fig. $3 E$ ).

\section{Discussion}

This is the first evidence that sleep is increased by selectively activating a specific phenotype of neurons. Stimulating a subset of $\mathrm{MCH}$ neurons robustly increased sleep during the animal's waking period attesting to the potency of the $\mathrm{MCH}$ neurons in counteracting the combined signal of the arousal neurons. $\mathrm{MCH}$ neurons contain GABA (Del Cid-Pellitero and Jones, 2012), but $\mathrm{MCH}$ also exerts an inhibitory effect on target neurons (Gao and van den Pol, 2001). Thus, MCH neuron facilitation of sleep is possibly mediated by presynaptic and postsynaptic actions of $\mathrm{MCH}$ onto arousal neurons (Gao and van den Pol, 2001), and also by direct GABA co-release with $\mathrm{MCH}$ onto arousal neurons (Del Cid-Pellitero and Jones, 2012). MCH neuron inhibition could be locally on the orexin neurons (Fig. $1 B$ ), but also from innervations of distal arousal neurons (Fig. $1 C, D$ ). Recent data show release of MCH in sleep in humans (Blouin et al., 2013).

The 10 and $30 \mathrm{~Hz}$ stimulations were effective in inducing sleep whereas $5 \mathrm{~Hz}$ was not. In rats, $\mathrm{MCH}$ neurons are silent during waking, but active during sleep, especially REM sleep when they discharge at $\sim 1 \mathrm{~Hz}$ (Hassani et al., 2009). However, MCH neurons can discharge at $21 \mathrm{~Hz}$ bursts or doublets of spikes (Hassani et al., 2009). Our in vitro experiments (Fig. 2) indicated that MCH-ChR2-EYFP neurons faithfully maintained steady discharge rates when stimulated, and it is possible that the faster rates were necessary to secrete sufficient $\mathrm{MCH}+\mathrm{GABA}$ onto target arousal neurons to overcome the arousal signal. Administration of $\mathrm{MCH}$ onto the various arousal neuronal populations produces a dose-dependent increase in both non-REM and REM sleep (Verret et al., 2003; Lagos et al., 2009, 2012). MCH knockout mice are awake more and have longer wake bouts at night, but REM sleep is unchanged (Willie et al., 2008). MCH-receptor-1 knock-out mice do not have less sleep, like MCH-null mice (Adamantidis et al., 2008), suggesting that non- $\mathrm{MCH}$ receptors also convey the MCH neuron sleep signal.

Inhibition of the arousal neurons, such as orexin (Sasaki et al., 2011; Tsunematsu et al., 2011) or the locus ceruleus noradrenergic neurons (Carter et al., 2010), does not induce sleep over an extended time period, especially during the animal's wake-active period. This suggests that to increase sleep during the wake-active period, it is not sufficient to temporarily suppress activity of the arousal neurons. Instead, the sleep-generating neurons have to be switched on. In the present study, $24 \mathrm{~h}$ of MCH stimulation (1 min stimulation every $5 \mathrm{~min}$ ) increased both non-REM and REM sleep at night. Delta power, an electrophysiological measure of sleepiness, was significantly increased during the day cycle, at a time when it wanes (Fig. $2 F$ ). There was no difference in delta power between 6 and 24 h of stimulation indicating that there was no cumulative effect of longer stimulation.

It has been difficult to selectively manipulate any of the sleepactive neurons as they are intermingled with arousal and other neurons. To specifically target the $\mathrm{MCH}$ neurons in all vertebrates the viral vector, rAAV-MCH-ChR2(H134R)-EYFP, was created. With it the largest single phenotype of neurons implicated in sleep were identified and controlled. The $\mathrm{MCH}$ neurons are present alongside the arousal orexin neurons in an area of the hypothalamus that also contains neurons regulating energy balance (Elias et al., 2001). MCH and orexin neurons show opposite patterns on several measures such as sleep-wake related neuronal activity and release of the peptides (Hassani et al., 2009; Blouin et al., 2013), energy expenditure (Elias et al., 2001), and response to glucose (Burdakov et al., 2005). The sleep-active neurons are distributed broadly and even though they all contain GABA their location in the brain likely determines how they inhibit the arousal neurons and initiate sleep. For instance, the $\mathrm{MCH}$ neurons respond to changes in energy balance while the sleep-active neurons in the preoptic area (Sherin et al., 1996) are likely regulating the circadian timing of sleep since they receive input from the retina (Lu et al., 1999). By selectively targeting specific neurons it will be feasible to elucidate how peripheral and central signals regulate sleep and arousal.

$\mathrm{MCH}$ stimulation increased both non-REM and REM sleep against a very strong circadian waking drive. This has significant potential for the insomnia associated with shift-work and jet-lag, conditions where a strong waking drive blocks sleep onset. Current pharmacotherapies may help, but involve next-day sedation, the risk of tolerance and dependence, or both. New agents that promote sleep without residual next-day impairment are needed. Inclusion of MCH neurons in network sleep-wake models offers new opportunities for potential hypnotics.

\section{References}

Adamantidis AR, Zhang F, Aravanis AM, Deisseroth K, de Lecea L (2007) Neural substrates of awakening probed with optogenetic control of hypocretin neurons. Nature 450:420-424. CrossRef Medline

Adamantidis A, Salvert D, Goutagny R, Lakaye B, Gervasoni D, Grisar T, Luppi PH, Fort P (2008) Sleep architecture of the melaninconcentrating hormone receptor 1-knockout mice. Eur J Neurosci 27: 1793-1800. CrossRef Medline

Bittencourt JC, Presse F, Arias C, Peto C, Vaughan J, Nahon JL, Vale W, Sawchenko PE (1992) The melanin-concentrating hormone system of the rat brain: an immuno- and hybridization histochemical characterization. J Comp Neurol 319:218-245. CrossRef Medline

Blouin AM, Fried I, Wilson CL, Staba RJ, Behnke EJ, Lam HA, Maidment NT, Karlsson KÆ, Lapierre JL, Siegel JM (2013) Human hypocretin and melanin-concentrating hormone levels are linked to emotion and social interaction. Nat Commun 4:1547. CrossRef Medline

Borbély AA (1982) A two process model of sleep regulation. Hum Neurobiol 1:195-204. Medline

Burdakov D, Gerasimenko O, Verkhratsky A (2005) Physiological changes in glucose differentially modulate the excitability of hypothalamic melanin-concentrating hormone and orexin neurons in situ. J Neurosci 25:2429-2433. CrossRef Medline

Carter ME, Yizhar O, Chikahisa S, Nguyen H, Adamantidis A, Nishino S, Deisseroth K, de Lecea L (2010) Tuning arousal with optogenetic modulation of locus coeruleus neurons. Nat Neurosci 13:1526-1533. CrossRef Medline

Del Cid-Pellitero E, Jones BE (2012) Immunohistochemical evidence for synaptic release of GABA from melanin-concentrating hormone containing varicosities in the locus coeruleus. Neuroscience 223:269-276. CrossRef Medline

Elias CF, Lee CE, Kelly JF, Ahima RS, Kuhar M, Saper CB, Elmquist JK (2001) Characterization of CART neurons in the rat and human hypothalamus. J Comp Neurol 432:1-19. CrossRef Medline 
Gao XB, van den Pol AN (2001) Melanin concentrating hormone depresses synaptic activity of glutamate and GABA neurons from rat lateral hypothalamus. J Physiol 533:237-252. CrossRef Medline

Hassani OK, Lee MG, Jones BE (2009) Melanin-concentrating hormone neurons discharge in a reciprocal manner to orexin neurons across the sleep-wake cycle. Proc Natl Acad Sci U S A 106:2418-2422. CrossRef Medline

Jones BE (2011) Neurobiology of waking and sleeping. Handb Clin Neurol 98:131-149. CrossRef Medline

Lagos P, Torterolo P, Jantos H, Chase MH, Monti JM (2009) Effects on sleep of melanin-concentrating hormone $(\mathrm{MCH})$ microinjections into the dorsal raphe nucleus. Brain Res 1265:103-110. CrossRef Medline

Lagos P, Monti JM, Jantos H, Torterolo P (2012) Microinjection of the melanin-concentrating hormone into the lateral basal forebrain increases REM sleep and reduces wakefulness in the rat. Life Sci 90:895-899. CrossRef Medline

Liu M, Blanco-Centurion C, Konadhode R, Begum S, Pelluru D, Gerashchenko D, Sakurai T, Yanagisawa M, van den Pol AN, Shiromani PJ (2011) Orexin gene transfer into zona incerta neurons suppresses muscle paralysis in narcoleptic mice. J Neurosci 31:6028-6040. CrossRef Medline

Lu J, Shiromani P, Saper CB (1999) Retinal input to the sleep-active ventrolateral preoptic nucleus in the rat. Neuroscience 93:209-214. CrossRef Medline

Sasaki K, Suzuki M, Mieda M, Tsujino N, Roth B, Sakurai T (2011) Phar- macogenetic modulation of orexin neurons alters sleep/wakefulness states in mice. PLoS One 6:e20360. CrossRef Medline

Sherin JE, Shiromani PJ, McCarley RW, Saper CB (1996) Activation of ventrolateral preoptic neurons during sleep. Science 271:216-219. CrossRef Medline

Steriade M, McCormick DA, Sejnowski TJ (1993) Thalamocortical oscillation in the sleeping and aroused brain. Science 262:679-685. CrossRef Medline

Tsunematsu T, Kilduff TS, Boyden ES, Takahashi S, Tominaga M, Yamanaka A (2011) Acute optogenetic silencing of orexin/hypocretin neurons induces slow-wave sleep in mice. J Neurosci 31:10529-10539. CrossRef Medline

van den Pol AN, Acuna-Goycolea C, Clark KR, Ghosh PK (2004) Physiological properties of hypothalamic MCH neurons identified with selective expression of reporter gene after recombinant virus infection. Neuron 42:635-652. CrossRef Medline

Verret L, Goutagny R, Fort P, Cagnon L, Salvert D, Léger L, Boissard R, Salin P, Peyron C, Luppi PH (2003) A role of melanin-concentrating hormone producing neurons in the central regulation of paradoxical sleep. BMC Neurosci 4:19. CrossRef Medline

Willie JT, Sinton CM, Maratos-Flier E, Yanagisawa M (2008) Abnormal response of melanin-concentrating hormone deficient mice to fasting: hyperactivity and rapid eye movement sleep suppression. Neuroscience 156:819-829. CrossRef Medline 